\title{
СИНТЕЗ, СВОЙСТВА И ПРОГНОЗИРОВАНИЕ СПЕКТРОВ БИОЛОГИЧЕСКОЙ АКТИВНОСТИ И ЦИТОТОКСИЧНОСТИ БИСТИАДИАЗОЛОВ
}

\author{
Ю.В. Суворова, Е.А. Петухова, Е.А. Данилова \\ НИИ Макрогетероциклических соединений, \\ Ивановский государственный химико-технологический университет, \\ 153000, Россия, Иваново, Шереметевский проспект, 7.
}

DOI: 10.19163/MedChemRussia2021-2021-539

E-mail:yuliya_butina@mail.ru

Целью данной работы является поиск новых препаратов, обладающих фармакологической активностью, на основе двухъядерных гетероциклических соединений, содержащих два 1,3,4-тиадиазольных цикла, связанных различными спейсерами.

В качестве объектов исследования нами выбраны и синтезированы по методике, описанной ранее в литературе [1], бис(1,3,4-тиадиазол)амины, содержащие метиленовый, этиленовый, пропиленовый, бутиленовый, пентиленовый и этениленовый спейсеры. Полученные соединения идентифицированы данными ИК, ЯМР спектроскопии и масс-спектрометрии.

Прогноз спектров антибактериальной и других видов активности, а также цитотоксичности был выполнен с использованием программ Anti-Bac-Pred, PASS и CLC-Pred, находящихся в свободном доступе в сети Интернет [2], и показал целесообразность биотестирования полученных молекул на некоторые виды активности.

Для оценки применения данных in silico нами проведен эксперимент in vitro, который показал, однако, что синтезированные соединения не активны против штаммов бактерий Pseudomonas aeruginosae, Escherichia coli и Staphylococcus aureus. Другие виды активности полученных веществ в настоящее время изучаются.

Работа выполнена при финансовой поддержке Гранта Президента РФ MK-1396.2020.3.

\section{References}

[1] Ю.В. Суворова, Е.А. Петухова, Е.А. Данилова, Д.В. Тюрин, Жидк. крист. и их практич. использ.. 2020, 20(4), 41-48.

[2] D.A. Filimonov, D.S. Druzhilovskiy, A.A. Lagunin, T.A. Gloriozova, A.V. Rudik, A.V. Dmitriev, P.V.Pogodin, V.V. Poroikov, Biomed. Chem. Res. Meth. 2018, 1(1), 1-21. 